\title{
ANTI-MÜLLERIAN HORMONE LEVELS AS A PREDICTOR OF FEMALE GENERAL HEALTH STATUS: A CROSS-SECTIONAL STUDY
}

\author{
Antonio Quartucci ${ }^{1}$, Enrico Papaleo ${ }^{1}$, Laura Privitera ${ }^{1}$, Agnese Rebecchi $^{1}$, Alessia \\ Limena $^{2}$, Maria Longo ${ }^{2}$, Eugenia Alleva ${ }^{2}$, Eugenio Ventimiglia ${ }^{1}$, Paola VIGANO ${ }^{1}$, Massimo \\ Candiani $^{1}$, Andrea Salonia ${ }^{1}$, and Valeria Vanni ${ }^{1}$ \\ ${ }^{1}$ San Raffaele Hospital \\ ${ }^{2}$ Università Vita Salute San Raffaele
}

April 29, 2020

\begin{abstract}
Objective: To assess the correlations between clinical and hormonal parameters and comorbidity burden in Caucasian women presenting for fertility treatment. Design: Cross-sectional study. Setting: Single academic reproductive medicine center. Patient: Cohort of 3163 single-ethnicity women seeking medical help for fertility treatment, who underwent centralized lab testing for fertility-related hormonal assessment. Intervention: Complete clinical and laboratory data from the entire cohort of patients were retrospectively analysed. Main outcome measures: Assessment of i) the comorbidity burden scored via the Charlson Comorbidity Index (CCI; categorized as 0 vs. 1 vs. $>2$ ); and, ii) the potential associations between CCI and clinical and hormonal parameters. Results: Descriptive statistics and regression models tested the associations between clinical and laboratory parameters and CCI. Of 3163, CCI=0, CCI=1 and CCI $>2$ were found in 2977 (94.1\%), $113(3.6 \%)$ and $73(2.3 \%)$ patients, respectively. Age, gravidity, Anti-Müllerian hormone (AMH) and thyroid stimulating hormone (TSH) values were found to be significantly different among CCI groups (all p[?] 0.01). At regression models, age at presentation and AMH emerged as independent predictors of $\mathrm{CCI}>1$. Age at presentation $<36$ years ( $\mathrm{OR}=1.742,95 \% \mathrm{CI}[1.284 ; 2.364])$ and an AMH level $<2.3 \mathrm{ng} / \mathrm{ml}(\mathrm{OR}=1.864,95 \%$ CI $[1.29 ; 2.69])$ were the most informative cutoff values for CCI $>1$. Conclusions: A younger age at presentation and lower AMH levels are significant predictors of decreased general health in women requiring clinical evaluation for fertility treatment. As observed for sperm parameters in men, AMH might serve as a proxy of women's general health status. Key words: AMH, comorbidities, health, infertility
\end{abstract}

\section{INTRODUCTION}

According to the World Health Organization (WHO) criteria, infertility is currently defined as the inability to conceive after at least one year of unprotected intercourse ${ }^{1}$ and has a prevalence of around $15 \%$ among couples $^{2}$. While genetic abnormalities are found in about 15-30\% of infertile men and $10 \%$ of infertile women, in the majority of cases infertility is due to acquired factors ${ }^{3,4}$. Over the last years, increasing evidence has suggested that a number of either hormonal or immunological disturbances that cause infertility might not only be related to reproductive health but also to overall morbidity and mortality ${ }^{5}$. For this reason, fertility status also in women is increasingly appraised as "a proxy of general health", a "harbinger for future health" ${ }^{6}$, or even as "the sixth vital sign" , thus representing a unique opportunity for developing preventive strategies and potential risk reduction.

Of importance, the causal pathways between health and infertility are not still definitively known ${ }^{5}$, and fertility status is rather looked at as a potential early biomarker for risk stratification later in life. 
In males, there are specific reproductive parameters that have been found to be associated with a decreased general health status as expressed by comorbidity scores ${ }^{7}$ - indices that provide general health assessment and predict mortality by applying weights or severity ratings for each comorbid condition ${ }^{8}$. More specifically, low sperm concentration, low testosterone and high follicle-stimulating hormone (FSH) values in primary infertile men have been found to be inversely associated with the comorbidity burden expressed by the Charlson Comorbidity Index $(\mathrm{CCI})^{9,10}$.

Epidemiological data has suggested that also female fertility and health status are closely intertwined. In this context, infertility at any reproductive age emerged to be associated with later cardiovascular conditions ${ }^{11}$, and an earlier decline in the ovarian follicular pool has been suggested in women with insulin resistance ${ }^{12}$, type 1 diabetes ${ }^{12,13}$, other immune disorders such as systemic lupus erythematosus ${ }^{14}$ or Sjögren's syndrome ${ }^{15}$, and cancer ${ }^{16}$.

Nonetheless, no study has so far explored whether any female specific reproductive parameter might be associated with general health, as previously observed for men ${ }^{10}$. Therefore, we sought to assess potential associations between fertility-related clinical and hormonal features and comorbidity burden in a homogeneous cohort of white-Caucasian women presenting for fertility treatment.

\section{MATERIALS AND METHODS}

\section{Patients}

The study population of this cross-sectional study consisted of a cohort of 3163 Caucasian women presenting for fertility treatments between August 2005 and April 2018 at a single academic reproductive medicine center. Couple infertility and cause of infertility were diagnosed after a comprehensive diagnostic evaluation of the male and female partners. According to the World Health Organization (WHO) criteria, infertility was defined as not conceiving a pregnancy after at least 12 months of unprotected intercourse. Comorbidities were assessed with a thorough self-reported medical history (including, gravidity and parity) and scored with the Charlson Comorbidity Index (CCI), using the International Classification of Diseases modified $9^{\text {th }}$ version (ICD-9-CM) classification. For the specific purpose of this analysis, CCI was categorized as 0,1 or [?]2. Gravidity was defined as the number of times that a woman had been pregnant and parity as the number of times that she had given birth to a fetus with a gestational age of 24 weeks or more. Age at menarche, menstrual frequency, smoking status and alcohol consumption were also recorded. Body mass index (BMI), defined as weight in kilograms by height in square meters, was measured for each patient.

All patients were admitted to the centralized laboratory of the same academic hospital to assess AntiMullerian hormone (AMH), Follicle Stimulating Hormone (FSH), Luteinizing Hormone (LH), Estradiol ( $\left.\mathrm{E}_{2}\right)$, 25( OH)-Vitamin D, Thyroid Stimulating Hormone (TSH), free triiodothyronine (fT3), free thyroxine (fT4), and Prolactin (PRL). Follicle-stimulating hormone, LH and PRL were measured using electrochemiluminescent immunoassays (ECLIA, COBAS ROCHE). 17b-estradiol, 25(OH)-Vitamin D, TSH, fT3 and fT4 were measured with electrochemiluminescent immunoassays (COBAS C 8000). Anti-Mullerian hormone was measured with the generation I enzyme-linked immunosorbent assay (AMH Gen I ELISA; Beckman Coulter) until the $30^{\text {th }}$ of October 2013 (defined as Kit 1), with generation II enzyme-linked immunosorbent assay (AMH Gen II; Beckman Coulter) until the $23^{\text {rd }}$ of January 2017 (defined as Kit 2), and then with the electrochemiluminescent immunoassay (Elecsys(r) AMH Plus, COBAS ROCHE, defined as Kit 3).

Data collection followed the principles outlined in the Declaration of Helsinki and all patients signed an informed consent agreeing to deliver their own anonymous information for the study. The study was approved by the IRCCS San Raffaele Ethical Committee (BCGINEOS, July 12 ${ }^{\text {th }} 2010$ ).

\section{Statistical analysis}

Data are presented as n (\%) for categorical variables and Mean (+- Standard Deviation) or Median (Range) for continuous variables, as appropriate. The statistical significance of differences in distribution was tested with Pearson chi-square test and non-parametric Kruskal-Wallis H test as appropriate. A 95\% confidence interval was estimated for the association of categorical parameters. Either linear or logistic regression models 
were applied to test the association between clinical predictors and continuously coded CCI or categorized CCI (defined as CCI $=0$ vs. CCI $>1$ ), respectively. Exploratory univariate analyses were initially applied to all variables, and variables that had significant association with comorbidity occurrence at univariate linear or logistic regression analyses were eventually included in the multivariate analyses. All variables showing a significant different distribution at non-parametric tests among subgroups of patients stratified by CCI score were then included for multivariate analyses. To identify the most informative cut-off value of age at presentation and AMH levels predicting CCI $>1$, both maximization of Youden's index and minimum $\mathrm{P}$ value approach were used ${ }^{17}$. Further logistic regression model was used to test the association between categorized AMH concentration and CCI $>1$. Statistical tests were performed using SPSS version 21 (IBM Corp.). All tests were two sided and a $\mathrm{P}$ value $<0.05$ was considered statistically significant.

\section{RESULTS}

Descriptive statistics of the whole cohort is shown in Table 1. Of all, CCI was 0, 1, and [?]2 in 2977 (94.1\%), $113(3.6 \%)$ and CCI $73(2.3 \%)$ patients, respectively.

Table 2 details the comorbidities found in the entire population, according to diagnostic categories and ICD-9-CM codes.

Table 3 depicts patient characteristics according to comorbidity status (as defined by CCI scoring). Of variables studied, age, gravidity, AMH and TSH values were found to significantly differ among CCI groups (Table 3). No further differences have been observed among CCI groups. Distribution of causes of infertility differed among patients stratified by CCI score $(\mathrm{p}<0.001)$. Among others, healthy women $(\mathrm{CCI}=0)$ presented more often with male-only infertility compared to women with comorbidities $(15.7 \%, 12.4 \%$ and $5.5 \%$ across groups with $\mathrm{CCI}=0, \mathrm{CCI}=1$ and $\mathrm{CCI}[?] 2$, respectively). Women with relevant comorbidities (CCI [?]2) were more often presenting for fertility preservation purposes $(23.3 \%$ compared to $0.7 \%$ in group with CCI $=0$ and $1.8 \%$ in group with $\mathrm{CCI}=1$ ).

Univariable and multivariable regression analysis are shown in Table 4. Among infertility-related factors, only age at presentation and AMH emerged to be independently associated with comorbidity burden, both at linear and logistic multivariate models (Table 4). Differences in terms of kit used for AMH assessment did not correlate with CCI score ( $\mathrm{p}=0.33$ and $\mathrm{p}=0.76$, respectively at linear and logistic regression models). The most informative cutoff values predicting a CCI $>1$ were age at presentation below 36 years $(\mathrm{OR}=1.742$, $\mathrm{p}<0.001,95 \% \mathrm{CI}[1.284 ; 2.364])$ and AMH levels below or equal to $2.3 \mathrm{ng} / \mathrm{ml}(\mathrm{OR}=1.864, \mathrm{p}=0.001,95 \%$ CI $[1.29 ; 2.69])$.

\section{DISCUSSION}

We investigated whether fertility-related clinical and hormonal data might predict women's general health as it has been previously observed for sperm parameters in men ${ }^{10}$. The findings of this cross-sectional study showed that age at presentation and AMH levels are significant predictors of general wellbeing in infertile women. Conversely, BMI, FSH, LH, and other hormones such as PRL, TSH, fT3, fT4 or Vitamin D did not predict the presence of comorbidities, as scored for CCI [?]1. Indeed, to score patients' somatic general health ${ }^{7}$, we used CCI, the most widely used scoring system to assess the rate and burden of comorbidities and predict mortality. While causal inferences cannot be drawn, strength of our study on a relatively-large homogenous same-ethnicity cohort of women, was the novel finding that AMH might be a marker of general female health, as observed for sperm concentration in males ${ }^{10}$.

Anti-Mullerian hormone is produced by granulosa cells of pre-antral and antral follicles and its concentrations have shown to be proportional to the number of developing follicles in the ovaries ${ }^{18,19}$. Despite this study is the first to describe an association between circulating AMH and overall women's health status, an association between lower AMH levels and a greater risk of cardiovascular ${ }^{20}$ and coronary heart ${ }^{21}$ diseases had already been described. Likewise, AMH was also found to be decreased in women with cancer ${ }^{16}$, liver disorders ${ }^{22}$ or renal failure ${ }^{23}$.

Therefore, our findings would confirm those previous data, providing the novel finding that a relative reduc- 
tion in ovarian reserve - as expressed by lower AMH values - is associated with the wide variety of medical conditions, as classified by ICD-9-CM; thereof, it may indeed predict female global somatic health.

Hence, significant strenghts of our study are the relatively large homogenous population included and availability of several fertility-related hormones tested throughout the fertility work-up of every woman, among which only AMH emerged as a significant predictor of female general health. Thus, our findings are in line with recent evidence suggesting AMH to be related with systemic conditions and all-cause mortality in men $^{24,25}$ and deserve thorough consideration.

Altogether, while the observed associations suggest a complex interplay among conditions that may be connected to both female global health and reproductive functioning, in contrast they do not allow causal inferences about the role of AMH in women's general wellbeing. Common mechanisms might indeed underlie coexisting infertility and comorbidities ${ }^{5}$ or - in contrast - comorbidities per se might have untoward effects on female ovarian function.

Nonetheless, our study seems to suggest that - as observed for seminal count in men ${ }^{10}$ - there are also a few of specific reproductive parameters even in women which might be associated with general health status, thus serving as potential "proxy of general health".

This study might also have clinical implications for infertility treatments. Indeed, preliminary data suggested that treatment of comorbidities in infertile men may improve sperm motility ${ }^{26,27}$. Thus, further analysis on whether treatment of female comorbidities might affect assisted reproductive outcomes would be of interest.

Our study also has some limitations. First, it will be relevant to assess the generalizability of our findings in other populations, also considering and comparing fertile women. Second, comorbidities were assessed through self-reported medical history, possibly causing some degree of information bias.

\section{CONCLUSIONS}

This cross-sectional study suggests that younger age at presentation and lower AMH levels may be significant predictors of decreased general somatic health in women requiring fertility treatments.

\section{Disclosure of interest}

The authors have no conflict of interest to disclose.

\section{Contribution to authorship}

AQ, EP and VSV conceived and designed the study. AR, ML participated in literature search and data collection. EP, LP, VSV, AL, EA contributed to data collection and classification. AQ, VSV, EP performed statistical analyses and drafted the manuscript. EP, PV, EV, AS, MC participated in interpretation of the findings and critical revision the intellectual contents of the manuscript. All authors approved the final version of the manuscript.

\section{Ethical approval}

The study was approved by the IRCCS San Raffaele Ethical Committee (BCGINEOS, July $12^{\text {th }} 2010$ ).

\section{Funding}

No funding was required for the study.

\section{REFERENCES}

1. Zegers-Hochschild F, Adamson GD, de Mouzon J, Ishihara O, Mansour R, Nygren K, et al. International Committee for Monitoring Assisted Reproductive Technology (ICMART) and the World Health Organization (WHO) revised glossary of ART terminology, 2009*. Fertil Steril 2009;92(5):1520-4. Available from: http://dx.doi.org/10.1016/j.fertnstert.2009.09.009 
2. Thoma ME, McLain AC, Louis JF, King RB, Trumble AC, Sundaram R, et al. Prevalence of infertility in the United States as estimated by the current duration approach and a traditional constructed approach. Fertil Steril 2013;99(5):1324-31.

3. O'Flynn O'Brien KL, Varghese AC, Agarwal A. The genetic causes of male factor infertility: A review. Fertil Steril 2010;93(1):1-12. Available from: http://dx.doi.org/10.1016/j.fertnstert.2009.10.045

4. Foresta C, Ferlin A, Gianaroli L, Dallapiccola B. Guidelines for the appropriate use of genetic tests in infertile couples. Eur J Hum Genet 2002;10(5):303-12.

5. Cedars MI, Taymans SE, DePaolo L V., Warner L, Moss SB, Eisenberg ML. The sixth vital sign: what reproduction tells us about overall health. Proceedings from a NICHD/CDC workshop. Hum Reprod Open 2017;2017(2):1-8.

6. Senapati S. Infertility: a marker of future health risk in women? Fertil Steril 2018;110(5):783-9. Available from: https://doi.org/10.1016/j.fertnstert.2018.08.058

7. Murshidi MM, Choy JT, Eisenberg ML. Male Infertility and Somatic Health. Urol Clin North Am 2020;47(2):211-7. Available from: https://doi.org/10.1016/j.ucl.2019.12.008

8. Salonia A, Matloob R, Gallina A, Abdollah F, Sacca A, Briganti A, et al. Are Infertile Men Less Healthy than Fertile Men? Results of a Prospective Case-Control Survey. Eur Urol 2009;56(6):1025-32.

9. Charlson ME, Pompei P, Ales KL, MacKenzie CR. A new method of classifying prognostic comorbidity in longitudinal studies: development and validation. J Chronic Dis 1987;40:373-83.

10. Ventimiglia E, Capogrosso P, Boeri L, Serino A, Colicchia M, Ippolito S, et al. Infertility as a proxy of general male health: Results of a cross-sectional survey. Fertil Steril 2015;104(1):48-55. Available from: http://dx.doi.org/10.1016/j.fertnstert.2015.04.020

11. Gleason JL, Shenassa ED, Thoma ME. Self-reported infertility, metabolic dysfunction, and cardiovascular events: a cross-sectional analysis among U.S. women. Fertil Steril 2019;111(1):138-46. Available from: https://doi.org/10.1016/j.fertnstert.2018.10.009

12. Skałba P, Cygal A, Madej P, Dbkowska-Huć A, Sikora J, Martirosian G, et al. Is the plasma antiMüllerian hormone (AMH) level associated with body weight and metabolic, and hormonal disturbances in women with and without polycystic ovary syndrome? Eur J Obstet Gynecol Reprod Biol 2011;158(2):254-9.

13. Soto N, Iñiguez G, López P, Larenas G, Mujica V, Rey RA, et al. Anti-Müllerian hormone and inhibin B levels as markers of premature ovarian aging and transition to menopause in type 1 diabetes mellitus. Hum Reprod 2009;24(11):2838-44.

14. Martins NFE, Seixas MI, Pereira JP, Costa MM, Fonseca JE. Anti-müllerian hormone and ovarian reserve in systemic lupus erythematosus. Clin Rheumatol 2017;36(12):2853-4.

15. Karakus S, Sahin A, Durmaz Y, Aydin H, Yildiz C, Akkar O, et al. Evaluation of ovarian reserve using anti-müllerian hormone and antral follicle count in Sjögren's syndrome: Preliminary study. J Obstet Gynaecol Res 2017;43(2):303-7.

16. Cameron K, Sammel MD, Prewitt M, Gracia C. Differential Rates of Change in Measures of Ovarian Reserve in Young Cancer Survivors across the Reproductive Lifespan. J Clin Endocrinol Metab 2019;104(5):181322.

17. Mazumdar M, Glassman JR. Categorizing a Prognostic Variable: Review of Methods, Code for Easy Implementation and Applications to Decision-Making about Cancer Treatments. Stat Med 2000;19:113-32.

18. Dewailly D, Andersen CY, Balen A, Broekmans F, Dilaver N, Fanchin R, et al. The physiology and clinical utility of anti-Müllerian hormone in women. Hum Reprod Update 2014;20(3):370-85. 
19. Christiansen SC, Eilertsen TB, Vanky E, Carlsen SM. Does AMH reflect follicle number similarly in women with and without PCOS? PLoS One 2016;11(1):1-12.

20. De Kat AC, Verschuren WMM, Eijkemans MJC, Van Der Schouw YT, Broekmans FJM. The association of low ovarian reserve with cardiovascular disease risk: A cross-sectional population-based study. Hum Reprod 2016;31(8):1866-74.

21. De Kat AC, Monique Verschuren W, Eijkemans MJC, Broekmans FJM, Van Der Schouw YT. AntiMüllerian Hormone Trajectories Are Associated with Cardiovascular Disease in Women: Results from the Doetinchem Cohort Study. Circulation 2017;135(6):556-65.

22. Karampatou A, Han X, Kondili LA, Taliani G, Ciancio A, Morisco F, et al. Premature ovarian senescence and a high miscarriage rate impair fertility in women with HCV. J Hepatol 2018;68(1):33-41.

23. Stoumpos S, Lees J, Welsh P, Hund M, Geddes CC, Nelson SM, et al. The utility of anti-Müllerian hormone in women with chronic kidney disease, on haemodialysis and after kidney transplantation. Reprod Biomed Online 2018;36(2):219-26. Available from: https://doi.org/10.1016/j.rbmo.2017.11.003

24. Qayyum R, Akbar S. Serum anti-mullerian hormone and all-cause mortality in men. Endocrine 2016;54(1):225-

31. Available from: http://dx.doi.org/10.1007/s12020-016-1071-x

25. Kadariya D, Kurbanova N, Qayyum R. Association of Anti-Mullerian Hormone with C-Reactive Protein in Men. Sci Rep 2019;9(1):1-6. Available from: http://dx.doi.org/10.1038/s41598-019-49596-x

26. Morgante G, Tosti C, Orvieto R, Musacchio MC, Piomboni P, De Leo V. Metformin improves semen characteristics of oligo-terato-asthenozoospermic men with metabolic syndrome. Fertil Steril 2011;95(6):2150-2. Available from: http://dx.doi.org/10.1016/j.fertnstert.2010.12.009

27. Kaukua J, Pekkarinen T, Sane T, Mustajoki P. Sex hormones and sexual function in obese men losing weight. Obes Res 2003;11(6):689-94.

Table 1. Characteristics and descriptive statistics of the cohort of patients assessed at a single academic center $(n=3163)$.

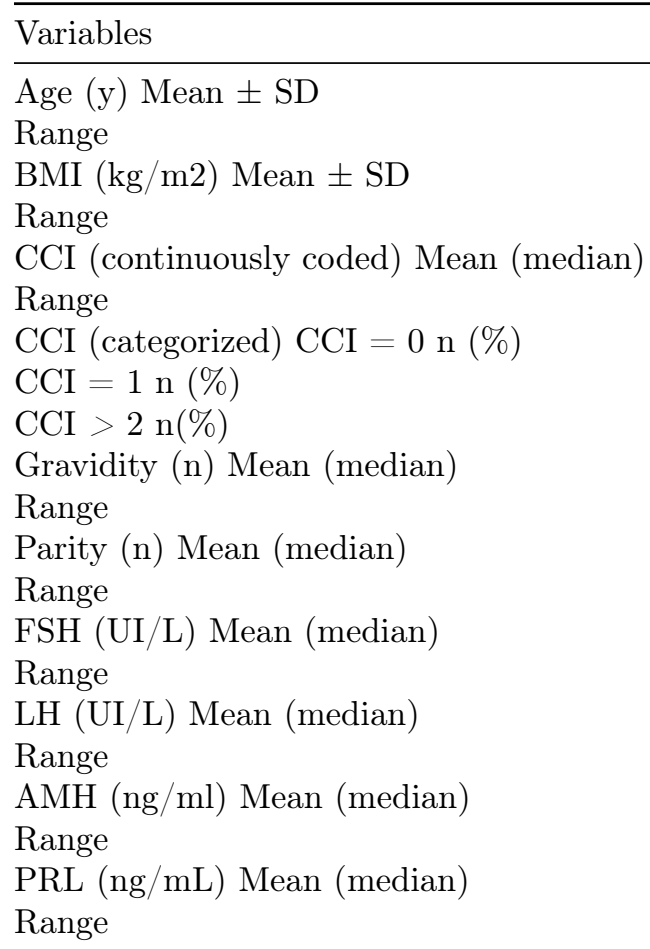


Variables

$\mathrm{T} \Sigma \mathrm{H}(\mu \mathrm{I} \Upsilon / \mu \Lambda) \mathrm{M} \varepsilon \alpha \nu(\mu \varepsilon \delta\llcorner\alpha \nu)$

$\mathrm{P} \alpha \nu \gamma \varepsilon$

fT3 (nmol/L) Mean (median)

Range

fT4 (nmol/L) Mean (median)

Range

$\operatorname{vitD}(\mathrm{ng} / \mathrm{mL})$ Mean (median)

Range

Keys: $\mathbf{A M H}=$ anti-mullerian hormone; $\mathrm{BMI}=$ body mass index; $\mathrm{CCI}=$ Charlson comorbidity index; FSH $=1$

Table 2. Diagnostic categories classified as the International Classification of Diseases modified $9^{\text {th }}$ version (ICD-9-CM) and Charlson comorbidity index (CCI) weights found in the entire cohort of patients $(n=3163)$.

\begin{tabular}{|c|c|c|}
\hline Condition & CCI weights & $\mathrm{N}(\%)$ \\
\hline $\begin{array}{l}\text { Myocardial infarction Old } \\
\text { Myocardial infarction }\end{array}$ & 1 & $2(0.06)$ \\
\hline Congestive heart failure & 1 & $0(0)$ \\
\hline Peripheral vascular disease & 1 & $1(0.03)$ \\
\hline Peripheral vascular disease NOS & & \\
\hline Cerebrovascular disease & 1 & $7(0.22)$ \\
\hline Dementia & 1 & $0(0)$ \\
\hline Chronic pulmonary disease & 1 & $49(1.55) 1(0.03) 1(0.03)$ \\
\hline $\begin{array}{l}\text { Moderate or severe asthma } \\
\text { COPD } \\
\text { Genetic svndrome }\end{array}$ & & \\
\hline $\begin{array}{l}\text { Genetic syndrome } \\
\text { Connective tissue disease Sjogren } \\
\text { syndrome }\end{array}$ & 1 & $4(0.12) 5(0.16) 12(0.38)$ \\
\hline $\begin{array}{l}\text { Systemic lupus erythematosus } \\
\text { Undifferentiated CTD }\end{array}$ & & \\
\hline Peptic ulcer disease & 1 & $4(0.12)$ \\
\hline $\begin{array}{l}\text { Mild liver disease Chronic } \\
\text { hepatitis }\end{array}$ & 1 & $14(0.44)$ \\
\hline Diabetes Diabetes mellitus & 1 & $20(0.63)$ \\
\hline $\begin{array}{l}\text { Diabetes with chronic } \\
\text { complications }\end{array}$ & 2 & $0(0.0)$ \\
\hline Renal disease Polycystic kidney & 2 & $3(0.09)$ \\
\hline
\end{tabular}




\begin{tabular}{lll}
\hline Condition & CCI weights & $\mathrm{N}(\%)$ \\
\hline Cancer (malignant neoplasm) Of & 2 & $2(0.06) 9(0.28) 1(0.03) 21(0.66)$ \\
the colon & & $10(0.32) 1(0.03) 3(0.09) 2(0.06)$ \\
Of the thyroid & & $4(0.06) 1(0.03) 1(0.03) 1(0.03)$ \\
Melanoma & \\
Of the breast & \\
Sarcoma & \\
Of the tongue & \\
Of the ovary & \\
Oligodendroglioma & \\
Of the pancreas & \\
Of the parothyd & \\
Choriocarcinoma & \\
Of parathyroid & \\
Leukemia & \\
Lymphoma & \\
Neuroendocrine tumor & \\
Moderate or severe liver disease & 3 & $0(0.22) 1(0.03)$ \\
Metastatic solid tumor Of thyroid & 6 & $1(0.03)$ \\
HIV disease & 6 & $0(0)$ \\
\hline
\end{tabular}

Table 3. Characteristics and descriptive statistics of patients according to patients' comorbidity load.

\begin{tabular}{|c|c|c|c|c|}
\hline Characteristic & CCI $0(n=2977)$ & CCI $1(n=113)$ & $\mathrm{CCI}[?] 2(\mathrm{n}=73)$ & $P$ value \\
\hline \multicolumn{5}{|l|}{ Age (y) } \\
\hline Mean $\pm \mathrm{SD}$ & $36.5 \pm 4.4$ & $36 \pm 4.4$ & $34.2 \pm 5.9$ & 0.009 \\
\hline Range & $16.9-48.5$ & $21.1-44.8$ & $15.2-44.9$ & \\
\hline \multicolumn{5}{|l|}{$\operatorname{BMI}\left(\mathrm{kg} / \mathrm{m}^{2}\right)$} \\
\hline Mean \pm SD & $22.3 \pm 3.8$ & $22.9 \pm 4.5$ & $22.2 \pm 3.1$ & 0.99 \\
\hline Range & $15.6-53.4$ & $13.9-38.3$ & $17.2-31.1$ & \\
\hline \multicolumn{5}{|l|}{ Gravidity } \\
\hline Mean (Median) & $0.65(0)$ & $0.85(0)$ & $0.3(0)$ & 0.001 \\
\hline Range & $0-8$ & $0-5$ & $0-4$ & \\
\hline \multicolumn{5}{|l|}{ Parity } \\
\hline Mean (Median) & $0.1(0)$ & $0.11(0)$ & $0.05(0)$ & 0.158 \\
\hline Range & $0-4$ & $0-1$ & $0-2$ & \\
\hline $\begin{array}{l}\text { Age at menarche } \\
\mathrm{n}(\%)\end{array}$ & & & & 0.66 \\
\hline$[?] 9 \mathrm{y}$ & $39(1.3)$ & $2(1.8)$ & $1(1.4)$ & \\
\hline $10-11$ y & $493(16.6)$ & $15(13.3)$ & $12(16.4)$ & \\
\hline $12-13 \mathrm{y}$ & $1187(39.9)$ & $44(38.9)$ & $25(34.2)$ & \\
\hline [?]14 y & $566(19)$ & $26(23.0)$ & $11(15.1)$ & \\
\hline $\mathrm{NA}$ & $692(23.2)$ & $26(23.0)$ & $24(32.9)$ & \\
\hline $\begin{array}{l}\text { Menstrual cycle } \\
\text { frequency n }(\%)\end{array}$ & & & & 0.84 \\
\hline Amenorrhea & $29(1)$ & $1(0.9)$ & $0(0)$ & \\
\hline Irregular & $43(1.4)$ & $1(0.9)$ & $0(0)$ & \\
\hline$[?] 25 \mathrm{~d}$ & $177(5.9)$ & $8(7.1)$ & $5(6.8)$ & \\
\hline $26-32 \mathrm{~d}$ & $2308(77.5)$ & $85(75.2)$ & $56(76.7)$ & \\
\hline
\end{tabular}




\begin{tabular}{|c|c|c|c|c|}
\hline Characteristic & CCI $0(\mathrm{n}=2977)$ & CCI $1(n=113)$ & $\mathrm{CCI}[?] 2(\mathrm{n}=73)$ & $P$ value \\
\hline $33-45 \mathrm{~d}$ & $291(9.8)$ & $14(12.4)$ & $4(5.5)$ & \\
\hline$>45$ & $53(1.8)$ & $2(1.8)$ & $0(0.0)$ & \\
\hline NA & $76(2.6)$ & $2(1.8)$ & $8(11)$ & \\
\hline $\begin{array}{l}\mathrm{N} \text { of smoked } \\
\text { cigarettes/day n } \\
(\%)\end{array}$ & & & & 0.592 \\
\hline 0 & $2226(74.8)$ & $83(73.5)$ & $48(65.7)$ & \\
\hline$<5$ & $318(10.7)$ & $14(12.4)$ & $9(12.3)$ & \\
\hline $5-20$ & $295(9.9)$ & $9(8.0)$ & $7(9.6)$ & \\
\hline$>20$ & $58(1.9)$ & $5(4.4)$ & $1(1.4)$ & \\
\hline NA & $80(2.7)$ & $2(1.8)$ & $8(11)$ & \\
\hline $\begin{array}{l}\text { Alcohol consump- } \\
\text { tion/week n } \\
(\%)\end{array}$ & & & & 0.76 \\
\hline 0 glasses & $476(16.0)$ & $12(10.6)$ & $14(19.2)$ & \\
\hline 1-7 glasses & $470(15.8)$ & $19(16.8)$ & $10(13.7)$ & \\
\hline 8-14 glasses & $4(0.1)$ & $0(0)$ & $0(0)$ & \\
\hline $\mathrm{NA}$ & $2027(68.1)$ & $82(72.6)$ & $49(67.1)$ & \\
\hline \multicolumn{5}{|l|}{ FSH $(\mathrm{mIU} / \mathrm{mL})$} \\
\hline Mean (Median) & $8.9(7.7)$ & $7.7(6.9)$ & $10.7(8.1)$ & 0.067 \\
\hline Range & $0.3-174$ & $2-26$ & $4.9-111$ & \\
\hline \multicolumn{5}{|l|}{$\mathrm{LH}(\mathrm{mIU} / \mathrm{mL})$} \\
\hline Mean (Median) & $6.3(5.3)$ & $6.2(5.3)$ & $6.8(5.4)$ & 0.688 \\
\hline Range & $0-114$ & $0.9-22$ & $2.1-43$ & \\
\hline \multicolumn{5}{|l|}{$\mathrm{AMH}(\mathrm{ng} / \mathrm{ml})$} \\
\hline Mean (Median) & $2.16(1.4)$ & $2.17(1.5)$ & $1.29(0.99)$ & $<0.001$ \\
\hline Range & $0-19$ & $0-17$ & $0-7$ & \\
\hline AMH kit n (\%) & & & & 0.31 \\
\hline 1 & $1622(54.5)$ & $65(57.5)$ & $33(45.2)$ & \\
\hline 2 & $1077(36.2)$ & $36(31.9)$ & $29(39.7)$ & \\
\hline 3 & $278(9.3)$ & $12(10.6)$ & $11(15.1)$ & \\
\hline \multicolumn{5}{|l|}{ PRL (ng/ml) } \\
\hline Mean (Median) & $29.5(13)$ & $36.1(14)$ & $19.5(10.4)$ & 0.114 \\
\hline Range & $0.3-1147$ & $0.2-741$ & $4-295$ & \\
\hline \multicolumn{5}{|l|}{$\mathrm{TSH}(\mu \mathrm{IU} / \mathrm{L})$} \\
\hline Mean (Median) & $2.2(1.8)$ & $2.16(2.11)$ & $1.6(1.5)$ & 0.003 \\
\hline Range & $0-305$ & $0-6$ & $0-5.6$ & \\
\hline \multicolumn{5}{|l|}{ T3 (mIU/L) } \\
\hline Mean (Median) & $3.8(2.9)$ & $3(3)$ & $3.2(3)$ & 0.81 \\
\hline Range & $0.3-145$ & $2.1-5$ & $2.5-5.2$ & \\
\hline \multicolumn{5}{|l|}{ T4 (mIU/L) } \\
\hline Mean (Median) & $3.8(1.1)$ & $3.8(1.1)$ & $4.8(1.8)$ & 0.51 \\
\hline Range & $0.3-123$ & $0.8-13$ & $0.9-23$ & \\
\hline \multicolumn{5}{|l|}{$\begin{array}{l}\text { Vitamin D } \\
(\mathrm{ng} / \mathrm{ml})\end{array}$} \\
\hline Mean (Median) & $30(23)$ & $45(25)$ & $23.8(21.1)$ & 0.29 \\
\hline Range & $3-602$ & $6-329$ & $9-41$ & \\
\hline $\begin{array}{l}\text { Cause of } \\
\text { infertility n (\%) }\end{array}$ & & & & $<0.001$ \\
\hline Idiopathic & $558(18.7)$ & $20(17.7)$ & $11(15.1)$ & \\
\hline
\end{tabular}




\begin{tabular}{lllll}
\hline Characteristic & CCI $0(\mathrm{n}=2977)$ & CCI $1(\mathrm{n}=113)$ & CCI[?]2 $(\mathrm{n}=73)$ & P value \\
\hline $\begin{array}{l}\text { Reduced ovarian } \\
\text { reserve }\end{array}$ & $977(32.8)$ & $34(30.1)$ & $26(35.6)$ & \\
Male-only infertility & $466(15.7)$ & $14(12.4)$ & $4(5.5)$ & \\
Endometriosis & $385(12.9)$ & $13(11.5)$ & $7(9.6)$ & \\
Ovulation disorders & $386(13.0)$ & $21(18.6)$ & $6(8.2)$ & \\
Tubal factor & $155(5.2)$ & $8(7.1)$ & $1(1.4)$ & \\
Genetic & $28(0.1)$ & $1(0.9)$ & $17(23.4)$ & \\
Fertility & $22(0.7)$ & $2(1.8)$ & & \\
preservation & & & & \\
\hline
\end{tabular}

Table 4. Linear (beta; $\mathrm{P}$ value $[95 \% \mathrm{CI}]$ ) and logistic ( $\mathrm{OR}$; $\mathrm{P}$ value $[95 \% \mathrm{CI}]$ ) regression models predicting presence of comorbidities $(\mathrm{CCI}>1)$ in the whole cohort of patients $(n=3163)$.

\begin{tabular}{|c|c|c|c|c|c|}
\hline & Linear model & Linear model & Logistic model & Logistic model & Logistic model \\
\hline Characteristic & UVA model & MVA model & UVA model & $\begin{array}{l}\text { MVA model/ } \\
\text { continuous } \\
\text { AMH }\end{array}$ & $\begin{array}{l}\text { MVA model/ } \\
\text { Categorized } \\
\text { AMH }\end{array}$ \\
\hline Age & $\begin{array}{l}-0.073 ;<0.001 \\
{[-0.009 ;-0.003]}\end{array}$ & $\begin{array}{l}-0.093 ;<0.001 \\
{[-0.011 ;-0.005]}\end{array}$ & $\begin{array}{l}0.956 ; 0.006 \\
{[0.926 ; 0.987]}\end{array}$ & $\begin{array}{l}0.941 ;<0.001 \\
{[0.91 ; 0.973]}\end{array}$ & $\begin{array}{l}0.94 ;<0.001 \\
{[0.91 ; 0.972]}\end{array}$ \\
\hline BMI & $\begin{array}{l}0.019 ; 0.295 \\
{[-0.002 ; 0.005]}\end{array}$ & - & $\begin{array}{l}1.029 ; 0.142 \\
{[0.991 ; 1.068]}\end{array}$ & & \\
\hline Gravidity & $\begin{array}{l}-0.024 ; 0.175 \\
{[-0.023 ; 0.004]}\end{array}$ & $\begin{array}{l}-0.015 ; 0.397 \\
{[-0.019 ; 0.008]}\end{array}$ & $\begin{array}{l}1.033 ; 0.887 \\
{[0.887 ; 1.204]}\end{array}$ & $\begin{array}{l}1.03 ; 0.707 \\
{[0.884 ; 1.2]}\end{array}$ & $\begin{array}{l}1.03 ; 0.704 \\
{[0.884 ; 1.199]}\end{array}$ \\
\hline Parity & $\begin{array}{l}-0.024 ; 0.169 \\
{[-0.061 ; 0.011]}\end{array}$ & - & $\begin{array}{l}0.74 ; 0.23[0.452 ; \\
1.21]\end{array}$ & & \\
\hline $\mathrm{AMH}$ & $\begin{array}{l}-0.048 ; 0.007 \\
{[-0.013 ;-0.002]}\end{array}$ & $\begin{array}{l}-0.076 ;<0.001 \\
{[-0.017 ;-0.006]}\end{array}$ & $\begin{array}{l}0.93 ; 0.059 \\
{[0.862 ; 1.003]}\end{array}$ & $\begin{array}{l}0.893 ; 0.007 \\
{[0.822 ; 0.97]}\end{array}$ & \\
\hline $\begin{array}{l}\mathrm{AMH} \\
\text { categorized (< } \\
2.3 \mathrm{ng} / \mathrm{ml} \mathrm{vs}> \\
2.3 \mathrm{ng} / \mathrm{ml})\end{array}$ & $\begin{array}{l}-0.056 ; 0.002 \\
{[-0.074 ;-0.017]}\end{array}$ & - & $\begin{array}{l}0.623 ; 0.01 \\
{[0.436 ; 0.892]}\end{array}$ & & $\begin{array}{l}0.529 ; 0.001 \\
{[0.366 ; 0.766]}\end{array}$ \\
\hline AMH kit & $\begin{array}{l}0.006 ; 0.335 \\
{[-0.006 ; 0.018]}\end{array}$ & & $\begin{array}{l}1.114 ; 0.335 \\
{[0.895 ; 1.386]}\end{array}$ & & \\
\hline VitD & $\begin{array}{l}-0.015 ; 0.749 \\
{[-0.001 ; 0.001]}\end{array}$ & - & $\begin{array}{l}1.003 ; 0.45 \\
{[0.996 ; 1.009]}\end{array}$ & & \\
\hline FSH & $\begin{array}{l}-0.008 ; 0.659 \\
{[-0.001 ; 0.002]}\end{array}$ & - & $\begin{array}{l}0.996 ; 0.764 \\
{[0.974 ; 1.02]}\end{array}$ & & \\
\hline LH & $\begin{array}{l}0 ; 0.981[-0.002 ; \\
0.002]\end{array}$ & - & $\begin{array}{l}1 ; 0.982[0.969 ; \\
1.033]\end{array}$ & & \\
\hline PRL & $\begin{array}{l}-0.001 ; 0.948 \\
{[0 ; 0]}\end{array}$ & - & $\begin{array}{l}1 ; 0.667[0.998 ; \\
1.002]\end{array}$ & & \\
\hline TSH & $\begin{array}{l}-0.01 ; 0.56 \\
{[-0.003 ; 0.002]}\end{array}$ & $\begin{array}{l}-0.008 ; 0.642 \\
{[-0.003 ; 0.002]}\end{array}$ & $\begin{array}{l}0.94 ; 0.382 \\
{[0.813 ; 1.082]}\end{array}$ & $\begin{array}{l}0.936 ; 0.37 \\
{[0.809 ; 1.082]}\end{array}$ & $\begin{array}{l}0.938 ; 0.384 \\
{[0.812 ; 1.084]}\end{array}$ \\
\hline T3 & $\begin{array}{l}-0.008 ; 0.816 \\
{[-0.005 ; 0.004]}\end{array}$ & - & $\begin{array}{l}0.988 ; 0.802 \\
{[0.896 ; 1.089]}\end{array}$ & & \\
\hline $\mathrm{T} 4$ & $\begin{array}{l}0.009 ; 0.788 \\
{[-0.002 ; 0.003]}\end{array}$ & - & $\begin{array}{l}1.004 ; 0.777 \\
{[0.975 ; 1.034]}\end{array}$ & & \\
\hline
\end{tabular}

